\title{
Use of oral anticoagulants in African-American and Caucasian patients with atrial fibrillation: is there a treatment disparity?
}

This article was published in the following Dove Press journal:

Journal of Multidisciplinary Healthcare

18 May 2015

Number of times this article has been viewed

\section{Olakunle Akinboboye}

Queens Heart Institute, Rosedale, NY, USA
Correspondence: Olakunle Akinboboye Queens Heart Institute, 234-236 Merrick Boulevard, Rosedale, NY I 1422, USA

$\mathrm{Tel}+\mathrm{I} 7189499400$

$\mathrm{Fax}+\mathrm{I} 7189498300$

Email akinboboye@gmail.com

\begin{abstract}
Atrial fibrillation (AF) is a very common cardiac arrhythmia, and its prevalence is increasing along with aging in the developed world. This review discusses racial differences in the epidemiology and treatment of AF between African-American and Caucasian patients. Additionally, the effect of race on warfarin and novel oral anticoagulant use is discussed, as well as the role that physicians and patients play in achieving optimal treatment outcomes. Despite having a lower prevalence of AF compared with Caucasians, African-Americans suffer disproportionately from stroke and its sequelae. The possible reasons for this paradox include poorer access to health care, lower health literacy, and a higher prevalence of other stroke-risk factors among African-Americans. Consequently, it is important for providers to evaluate the effects of race, health literacy, access to health care, and cultural barriers on the use of anticoagulation in the management of AF. Warfarin-dose requirements vary across racial groups, with African-American patients requiring a higher dose than Caucasians to maintain a therapeutic international normalized ratio; the novel oral anticoagulants (dabigatran, rivaroxaban, and apixaban) seem to differ in this regard, although data are currently limited. Minority racial groups are not proportionally represented in either real-world studies or clinical trials, but as more information becomes available and other social issues are addressed, the treatment disparities between African-American and Caucasian patients should decrease.
\end{abstract}

Keywords: antithrombotic, atrial fibrillation, stroke, warfarin, race

\section{Introduction}

Atrial fibrillation (AF) is highly prevalent in the US, and with the incidence of AF continuing to grow, the costs of treatment are also increasing. ${ }^{1}$ Stroke is a serious but preventable complication of AF, but therapeutic anticoagulation for the prevention of stroke can lead to an increased risk of bleeding; ${ }^{2,3}$ therefore, clinicians must be aware of the optimum benefit:risk ratio for the treatment of these patients. Despite African-Americans having a lower incidence of AF than Caucasians, the burden remains high, with one in nine African-Americans receiving a diagnosis before 80 years of age. ${ }^{4}$

The objectives of this review are: 1) to provide clinicians with an overview of AF and the importance of stroke prevention; 2) to discuss stroke prevention in underrepresented patient populations, particularly African-American patients; 3) to highlight knowledge gaps related to stroke prevention in underrepresented patient populations; 4) to discuss racial differences in the prevalence of AF and response to anticoagulants; and 5) to discuss the role clinicians may play in the care of patients with AF. 


\section{Description, prevalence, and consequences of atrial fibrillation and stroke}

$\mathrm{AF}$, defined as an abnormal rate or rhythm of the heart, is the most common type of arrhythmia. In patients with AF, multiple disorganized electrical impulses lead to rapid and chaotic contractions that prevent the atria from contracting properly, and as a result blood does not travel normally through the heart and vasculature. ${ }^{1}$ Although many patients with AF do not experience any symptoms, some patients can experience heart palpitations, lack of energy, dizziness, or shortness of breath. Additionally, AF can lead to an increase in the risk of stroke by allowing clots to form within the heart, which may travel to the brain. Nonvalvular AF (NVAF), defined as AF in the absence of rheumatic mitral valve disease, a prosthetic heart valve, or mitral valve repair, is the most common type of $\mathrm{AF}^{3,5}$

The prevalence of $\mathrm{AF}$ is increasing along with aging in the developed world, and AF is associated with a fivefoldincreased risk of stroke, with a fifth of all strokes associated with $\mathrm{AF}^{6,7}$ Strokes are classified by the type of brain injury (eg, ischemic, hemorrhagic) and the type and location of the vascular lesion. ${ }^{8}$ Ischemic strokes are by far the more common type, causing over $80 \%$ of all strokes, and $20 \%$ of all ischemic strokes result directly from $\mathrm{AF}^{9,10}$ The absolute risk of stroke in patients with AF can vary 20 -fold, and this risk is dependent on the number of additional risk factors that a patient may have, such as heart failure, hypertension, older age, diabetes, prior stroke, vascular disease, and female sex.,11,12 Strokes related to AF tend to be associated with greater morbidity and mortality compared with non-AF-related strokes; ${ }^{13,14}$ however, the risk of stroke can be reduced with anticoagulant treatment. ${ }^{2,3,6,15}$

The total health care cost of all strokes in the US was $\$ 53.9$ billion in 2010, and of that figure, the cost of AF-related strokes was estimated to range from $\$ 3.2$ billion to nearly $\$ 13$ billion. By 2050, the economic burden of strokes related to $\mathrm{AF}$ in the US is estimated to approach $\$ 30$ billion. ${ }^{16}$

\section{Are there racial/ethnic differences in the epidemiology of AF?}

The incidence of AF is lower in African-Americans than in Caucasians; the reasons for this remain unclear. ${ }^{17-21}$ It has been suggested that the incidence of AF in AfricanAmericans may be underreported, and that the number of African-Americans with AF might be higher if more sensitive methods for detection were used..$^{18,20,22}$ A study investigating racial differences in the incidence of and risk factors for $\mathrm{AF}$ in older adults found that for all associations examined, risk factors were similar in African-Americans and Caucasians, except for left ventricular posterior-wall thickness, which was more strongly associated with AF in African-Americans. ${ }^{23}$

Conversely, the relative rate of stroke is higher in African-Americans than in Caucasians, ${ }^{21}$ which appears to contradict the strong association between stroke and AF. One possible reason for the higher incidence and mortality rate of stroke in African-Americans may be the higher prevalence of other stroke-risk factors, including hypertension, obesity, and diabetes, in this population. ${ }^{17,19}$

In general, cryptogenic stroke (defined as ischemic stroke without a well-defined etiology) accounts for $34 \%-54 \%$ of ischemic strokes in most modern stroke registries and databases. ${ }^{24-29}$ Additionally, a population-based study showed that the rate of cryptogenic stroke in African-Americans was approximately double the rate observed in Caucasians (risk ratio $1.9,95 \%$ confidence interval $1.5-2.3) .{ }^{28}$ Use of sophisticated heart-monitoring techniques like implanted loop recorders might detect unrecognized paroxysmal $\mathrm{AF}$ as the cause of some cryptogenic strokes in African-Americans. ${ }^{30}$ This suggestion is further supported by results from the REGARDS (REasons for Geographic And Racial Differences in Stroke) study, a national, population-based, longitudinal study of African-American and Caucasian adults aged at least 45 years in the US, which found that the odds of an association of stroke with race (African-American versus Caucasian) and AF progressively decreased with increasing test sensitivity. ${ }^{22}$

\section{Treatment of AF: reducing the risk of stroke with oral anticoagulants}

There are many treatment options for patients with AF that aim to control irregular heart rate or prevent stroke. ${ }^{31}$ Options include cardioversion, ablation, and pharmacological agents, which may be used for rate or rhythm control. ${ }^{32}$ Additionally, antithrombotic therapy can be used to reduce the risk of stroke in patients with AF, and that is the focus of this article.

Antithrombotic therapy to prevent thromboembolism is recommended for all patients with AF, except those with lone AF or contraindications, and the selection of an antithrombotic agent should be based on absolute risks of stroke and bleeding and the relative risk and benefit for a given patient. ${ }^{31}$

Guidelines for oral anticoagulant use in patients with $\mathrm{AF}$ in both the US and Europe are summarized in Table $1 ; 2,3,6,33,34$ 


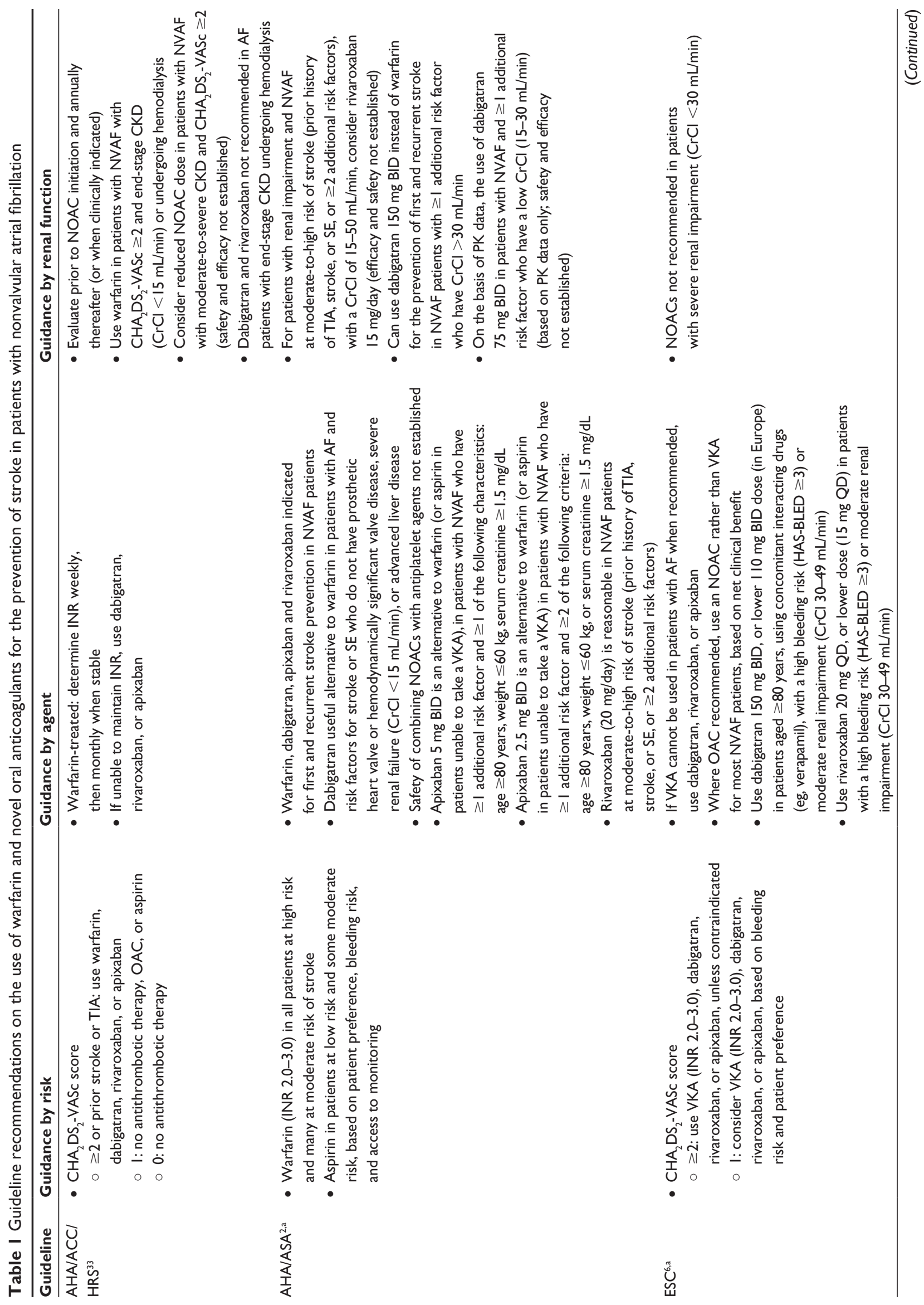




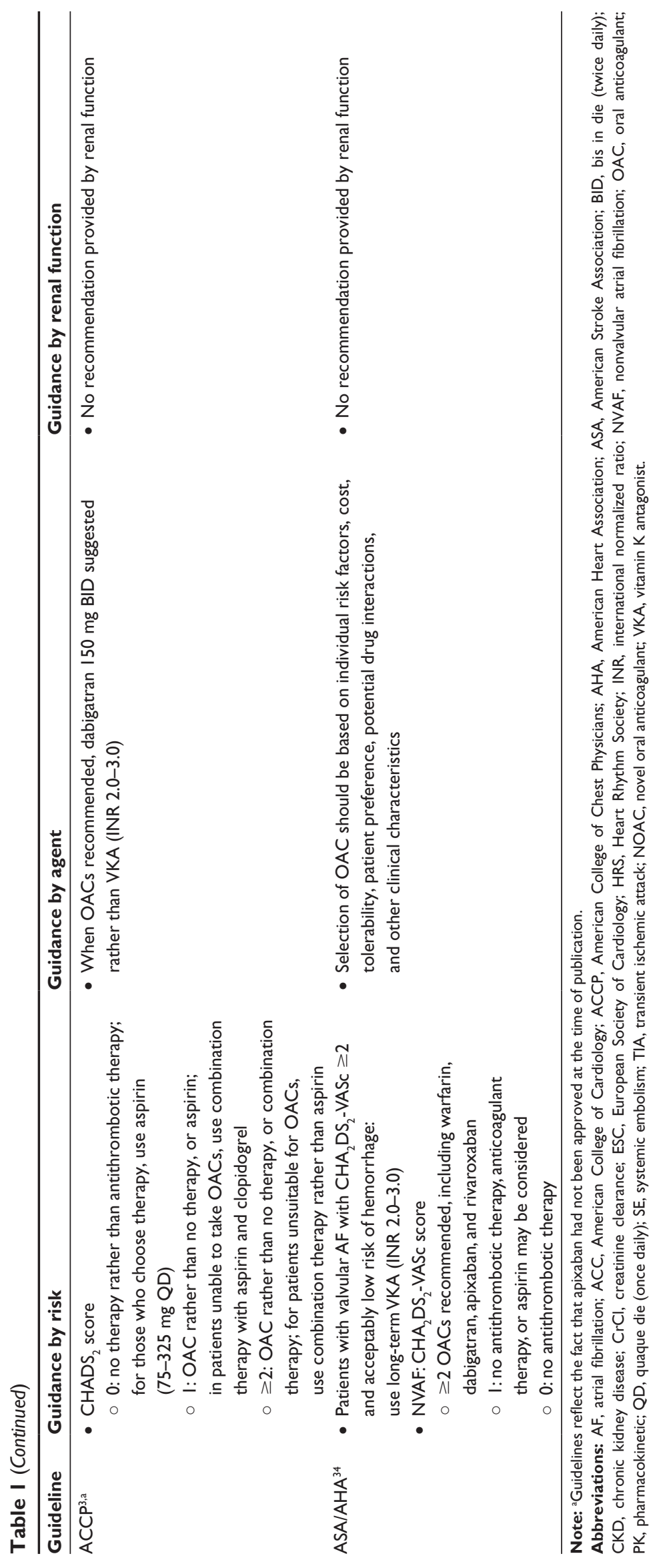


however, it should be noted that some of these were published prior to the approval of apixaban and edoxaban.

\section{Differences in treatment by race/ethnicity}

A treatment disparity exists between African-American and Caucasian patients; however, none of the current guidelines for the prevention of stroke in patients with $\mathrm{AF}$ states whether any amendments to treatment should be made based on racial differences. . $^{2,3,5,6,15,35}$

African-Americans are undertreated, and thus are at an increased risk of stroke. ${ }^{18,36,37}$ Differences in access to health care may account in part for lower rates of AF detection in African-Americans than in Caucasians. In the REGARDS study, race and income were both found to be independent predictors of patients being aware that they had AF, with African-Americans being less than a third as likely as Caucasians to be aware. ${ }^{18}$ Additionally, this study found that race was an independent predictor of warfarin treatment, with the odds of African-American patients being treated with warfarin only a quarter as great as the odds for Caucasians. ${ }^{18}$ A study using a multiethnic stroke-free cohort of hospitalized patients with nonrheumatic AF found that although the percentage of time on warfarin did not differ by race/ethnicity, the median percentage of time that patients spent within the therapeutic range (international normalized ratio [INR] 2.0-3.0) was lower in African-American than Caucasian patients (47.8\% versus $55.2 \%) .{ }^{38}$ Additionally, an analysis of the AFFIRM (Atrial Fibrillation Follow-up Investigation of Rhythm Management) study population found that ethnic minority status was an independent predictor of poor INR control, and race was subsequently included in a scoring system used to predict poor INR control in patients with AF treated with warfarin (SAMe$\mathrm{TT}_{2} \mathrm{R}_{2}$ : female sex, age $<60$ years, medical history [more than two comorbidities], treatment [with interacting drugs], tobacco use [doubled], and race [doubled]). ${ }^{39}$

Results from the Cardiovascular Health Study, a prospective, US-based cohort study of risk factors for cardiovascular disease in community-dwelling adults aged over 65 years, found that African-Americans have poorer access to health care than Caucasians, and were more likely to have no supplemental insurance coverage. ${ }^{40}$ A study investigating the differences in the type of hospital where minorities and low-income patients received care found that African-American patients and those living in lowincome areas more frequently received care in teaching and safety-net hospitals and hospitals with higher bed counts, more intensive care unit beds, and emergency department volume, compared with Caucasians and those living in highincome areas. ${ }^{41}$ Crude inpatient-mortality rates for patients hospitalized with acute ischemic stroke were significantly lower in African-American than Caucasian patients across all three socioeconomic status cohorts (low, medium, and high income); however, African-American patients were younger, and fewer had any form of $\mathrm{AF}^{41}$ When adjusted for risk, inpatient mortality was similar in African-American and Caucasian patients, but was significantly higher in lowincome-area patients than in high-income-area patients. ${ }^{41}$ Caucasian patients were more likely than African-American patients to arrive by emergency medical services, to be evaluated by a stroke team, and to have a documented National Institutes of Health Scale score. ${ }^{42}$ Additionally, AfricanAmericans were less likely to have visited a physician 1 year after their stroke than Caucasians. ${ }^{43}$ Together, these results highlight the socioeconomic differences between AfricanAmerican and Caucasian patients, and suggest that there is a need for better access to health care and improvements to education programs for African-American patients.

\section{Warfarin}

For over 50 years, warfarin has been the standard of care for the prevention of stroke in patients with $\mathrm{AF}$, and remains the most commonly used anticoagulant in this population. A meta-analysis of six randomized controlled trials showed that warfarin reduced the risk of all strokes (ischemic and hemorrhagic) by $64 \%$ versus placebo. ${ }^{44}$ Although highly efficacious for the prevention of stroke in patients with AF, warfarin has many limitations, including an increased risk of bleeding, multiple drug and food interactions, and the need for regular monitoring and dose adjustment to maintain treatment within the narrow therapeutic range (INR 2.0-3.0). ${ }^{45}$ These limitations can result in the underuse of warfarin. ${ }^{46}$ It has been shown that warfarin-dose requirements vary across racial/ethnic groups, with African-American patients requiring a higher dose than Caucasian patients to maintain an INR between 2.0 and 3.0. ${ }^{47} \mathrm{~A}$ chart review comparing older African-American and Caucasian patients found that although the dose of warfarin required to maintain a therapeutic INR decreased with age, African-Americans required a higher maintenance dose than Caucasians. ${ }^{48}$ Therefore, strategies for initiating warfarin therapy based on studies of patients of European ancestry could result in insufficient anticoagulation of older African-American patients, thereby potentially increasing their risk of thromboembolism. ${ }^{48}$

Several studies have investigated the treatment disparity between African-American and Caucasian patients. ${ }^{49-51}$ 
A cohort study of Medicare beneficiaries with AF found that the use, monitoring, and effectiveness of warfarin therapy were suboptimal, especially in African-American patients. ${ }^{49}$ One possible effect of this is that African-American patients with $\mathrm{AF}$ are at greater risk of warfarin-related intracranial hemorrhage. ${ }^{52}$ Additionally, African-American patients were significantly less likely than Caucasians to fill a warfarin prescription for newly incident NVAF or to receive a warfarin prescription at hospital discharge..$^{50,51}$

Several genetic factors have recently been identified as possible reasons why African-American patients require a higher dose of warfarin. ${ }^{53,54}$ Dose variability is affected by

Table 2 Comparison of pharmacokinetic/pharmacodynamic interactions and dosing of warfarin and novel oral anticoagulants

\begin{tabular}{lll}
\hline & Warfarin $^{45}$ & Dabigatran $^{58}$ \\
\hline Mode of action & $\begin{array}{l}\text { Inhibitor of factors II, VII, IX, and X, } \\
\text { and the anticoagulant proteins C and S } \\
\text { Oral or IV }\end{array}$ & Direct thrombin inhibitor \\
$\begin{array}{l}\text { Route of } \\
\text { administration }\end{array}$ & Oral (tablet) \\
Approved dose (US) & Target INR 2.0-3.0 & I50 mg BID (75 mg BID for patients with CrCI I5-30 mg/mL)
\end{tabular}

$\begin{array}{lll}\text { Half-life } & 40 \text { hours } & \text { I2-I7 hours } \\ \text { Monitoring } & \text { Daily INR determination upon initiation until stable } & \text { Prolongs aPTT, ECT, and TT; insensitive to INR } \\ & \text { INR 2.0-3.0 achieved; INR every I-4 weeks thereafter } & \text { measurements }\end{array}$

Reversal $\quad$ Vitamin K

Reasons for dose Dose and administration individualized to each patient reductions Food interactions

Drug interactions

Effect of race on treatment

greens, scallions, brussels sprouts, raw broccoli, grapefruit juice, prunes, asparagus, avocado, beef liver) Monitor INR closely if used concurrently with inhibitors or inducers of: CYP3A4, CYP2C9, or CYPIA2 Closely monitor concurrent use with drugs that can increase bleeding risk
Asian patients may require lower initiation and maintenance doses of warfarin SNPs in the CYP2C9 and VKORCI genes have been associated with variable warfarin-dose requirements
- A specific reversal agent for dabigatran is not available

- Hemodialysis can remove dabigatran; however, clinical experience is limited

- aPPCs, rFVIla, or concentrates of coagulation factors II, IX, or $\mathrm{X}$ may be considered, but have not been evaluated in clinical trials

- Protamine sulfate and vitamin $\mathrm{K}$ are not expected to affect the anticoagulant activity of dabigatran

- Consider administration of platelet concentrates in cases where thrombocytopenia is present or long-acting antiplatelet drugs have been used

Patients with $\mathrm{CrCl} 15-30 \mathrm{~mL} / \mathrm{min}$ should take reduced dose (75 mg BID)

None

Avoid concomitant use with P-gp inducers

Decrease dose when used concomitantly with P-gp inhibitors, dronedarone, or systemic ketoconazole in patients with moderate renal impairment $(\mathrm{CrCl} 30-50 \mathrm{~mL} / \mathrm{min})$ Bleeding risk increases if used concomitantly with drugs that affect bleeding risk

No information available

Abbreviations: aPCC, activated prothrombin complex concentrate; anti-FXa, anti-factor Xa; aPTT, activated partial thromboplastin time; BID, bis in die (twice daily); $\mathrm{CrCl}$, creatinine clearance; ECT, ecarin clotting time; INR, international normalized ratio; IV, intravenous; NSAID, nonsteroidal anti-inflammatory drug; rFVIla, recombinant factor VIla; PCC, prothrombin complex concentrate; P-gP, p-glycoprotein; PK, pharmacokinetic; PT, prothrombin time; QD, quaque die (once daily); SNP, single-nucleotide polymorphism; TT, thrombin time. 
single-nucleotide polymorphisms (SNPs) in genes encoding cytochrome P450 (CYP)-2C9, which metabolizes the $S$-enantiomer of warfarin, and vitamin K epoxide reductase complex 1, which is the target enzyme for warfarin. ${ }^{55,56}$ These genotypes explain up to $30 \%$ of total variability in warfarin-dose requirements in people of European or Asian origin; however, they explain substantially less genetic variability in AfricanAmericans (10\%). ${ }^{56}$ A genome-wide association study identified a novel association between an SNP in CYP2C9 (rs12777823) and warfarin-dose variability in African-American patients. ${ }^{54}$ Patients carrying this SNP require a significantly lower stable dose of warfarin than those without the variant. ${ }^{54}$

\section{Rivaroxaban $^{60}$ \\ Factor Xa inhibitor}

Oral (tablet or nasal gastric tube) taken

with food

$20 \mathrm{mg}$ QD

\section{5-9 hours}

Cannot be monitored using standard laboratory tests; PT, aPTT, and Heptest ${ }^{\circledR}$ (Heptest Laboratories, St Louis, MO, USA) are prolonged dose-dependently; anti-FXa activity is also influenced by rivaroxaban

- A specific antidote for rivaroxaban is not available

- Because of high plasma protein binding, rivaroxaban is not expected to be dialyzable

- Protamine sulfate and vitamin $\mathrm{K}$ are not expected to affect the anticoagulant activity of rivaroxaban

- Partial reversal of PT prolongation has been seen after administration of PCCs in healthy volunteers

- The use of other procoagulant reversal agents like aPPC or rFVIla has not been evaluated

Patients with $\mathrm{CrCl} / 5-50 \mathrm{~mL} / \mathrm{min}$ should take reduced dose (I5 $\mathrm{mg} \mathrm{QD}$ )

Should be taken with the evening meal; bioavailability decreases if not taken with food

Avoid concomitant use with combined

P-gp and strong CYP3A4 inhibitors

Avoid concomitant use with combined

$\mathrm{P}$-gP and strong CYP3A4 inducers Increase monitoring if used concomitantly with NSAIDs or aspirin

Avoid concurrent use with other plateletaggregation inhibitors or antithrombotic agents Healthy Japanese subjects were found to have on average $20 \%-40 \%$ higher exposure compared with other ethnicities, including Chinese

Apixaban $^{59}$
Factor Xa inhibitor
Oral (tablet or nasal gastric tube)
$5 \mathrm{mg}$ BID

$\sim 12$ hours

Prolongs PT, INR, and aPTT, but changes at therapeutic dose are small, subject to a high degree of variability; Rotachrom ${ }^{\circledR}$ heparin (Diagnostica Stago, Parsippany, NJ, USA) chromogenic assay produced a concentration-dependent increase in anti-FXa activity, but is not recommended to assess the anticoagulant effect of apixaban

- A specific antidote for apixaban is not available

- Hemodialysis does not appear to have a substantial impact on apixaban exposure

- Protamine sulfate and vitamin $\mathrm{K}$ would not be expected to affect the anticoagulant effect of apixaban

- There is no experience with antifibrinolytic agents in patients receiving apixaban

- There is neither scientific rationale for reversal nor experience with systemic hemostatics in patients receiving apixaban

- PCCs, aPCC, or rFVIla may be considered, but have not been evaluated in clinical trials

- Activated charcoal reduces absorption of apixaban, thereby lowering apixaban plasma concentration

$\geq 2$ of the following: age $\geq 80$ years, weight $<60 \mathrm{~kg}$, or serum creatinine $\geq 1.5 \mathrm{mg} / \mathrm{dL}$

None

Decrease dose when used concomitantly with strong dual inhibitors of P-gP and CYP3A4

Avoid concomitant use with strong dual inducers of P-gP and CYP3A4

Bleeding risk increases if used concomitantly with drugs that affect hemostasis

No dose adjustment is required based on race/ethnicity
Patients with $\mathrm{CrCl} 15$ to $50 \mathrm{~mL} / \mathrm{min}$

None

\author{
Edoxaban ${ }^{57}$ \\ Factor $\mathrm{Xa}$ inhibitor \\ Oral (solution or tablet) \\ 60 mg QD (30 mg QD for \\ patients with $\mathrm{CrCl} I 5$ to \\ $50 \mathrm{~mL} / \mathrm{min}$ ) \\ Not approved in patients \\ with $\mathrm{CrCl}>95 \mathrm{~mL} / \mathrm{min}$ \\ 10-14 hours \\ Prolongs PT and aPTT \\ but changes in PT, INR \\ and APTT at the expected \\ therapeutic dose are small \\ and subject to a high degree \\ of variability \\ - A specific antidote for \\ edoxaban is not available \\ - Hemodialysis does not \\ significantly contribute to \\ edoxaban clearance \\ - Protamine sulfate, \\ vitamin $\mathrm{K}$, and tranexamic \\ acid are not expected to \\ reverse the anticoagulant \\ activity of edoxaban
}

Avoid concomitant use of edoxaban with P-gP inducers (rifampin) Bleeding risk increases if used concomitantly with drugs that affect hemostasis

In a population $\mathrm{PK}$ analysis, edoxaban exposures in Asian and non-Asian patients were similar 


\section{Novel oral anticoagulants}

Four novel oral anticoagulants (NOACs) have recently been approved by the US Food and Drug Administration (FDA): a direct thrombin inhibitor (dabigatran), and three factor-Xa inhibitors (apixaban, edoxaban, and rivaroxaban) (Figure 1). Unlike warfarin and other vitamin $\mathrm{K}$ antagonists, NOACs (dabigatran, rivaroxaban, apixaban, and edoxaban) do not require dose adjustments to maintain a therapeutic dose and have fewer risks of food and drug interactions. ${ }^{57-60}$ Lower doses of NOACs may be required based on renal function, weight, and/or age. Their predictable pharmacokinetic (PK) and pharmacodynamic profiles mean that routine monitoring is not necessary with these agents (Table 2); ${ }^{45,57-61}$ however, no specific antidotes are currently available for the reversal of the anticoagulant effects of NOACs in the event of overdose or hemorrhagic complications. ${ }^{57-60}$ Several options for the reversal of the anticoagulant effects of these agents are under investigation. ${ }^{62-68}$

In their respective Phase III trials, all of the NOACs were found to be noninferior to warfarin for reducing the risk of stroke or systemic embolism (SE) in patients with NVAF; however, only the dabigatran $150 \mathrm{mg}$ twice daily (bis in die [BID]) $(P<0.001)$ and apixaban $5 \mathrm{mg} \operatorname{BID}(P=0.01)$ dosages showed superiority (Table 3). ${ }^{69-73}$ Additionally, dabigatran (110 mg BID), apixaban, and edoxaban (both dosages) significantly reduced the risk of major bleeding compared with warfarin. A summary of other key end points is provided in Table 3.

There is limited information about the effect of race on NOAC treatment, and the number of patients by race was not provided in all of the NOAC Phase III trial publications. ${ }^{6-74}$ In an analysis of key subgroups in the ROCKET AF (Rivaroxaban Once daily oral direct factor Xa inhibition Compared with vitamin K antagonism for prevention of stroke and Embolism Trial in Atrial Fibrillation) trial, the effects of rivaroxaban versus warfarin were found to be similar across racial groups (Caucasian, African-American, Asian, other) for the outcomes of stroke or SE and major or clinically relevant nonmajor bleeding ( $P$-values for interaction 0.486 and 0.591 , respectively) ${ }^{73}$ Similarly, an analysis of key subgroups in the ENGAGE AF-TIMI (Effective aNticoaGulation with factor XA next GEneration in Atrial Fibrillation - Thrombolysis In Myocardial Infarction) 48 study found that the treatment effects of both doses of edoxaban compared with warfarin were similar across racial groups (Caucasian versus non-Caucasian) for the outcomes of stroke or SE ( $P$-values for interaction 0.28 and 0.49 for edoxaban $60 \mathrm{mg}$ and 30 mg BID, respectively) and for major bleeding ( $P$-values for

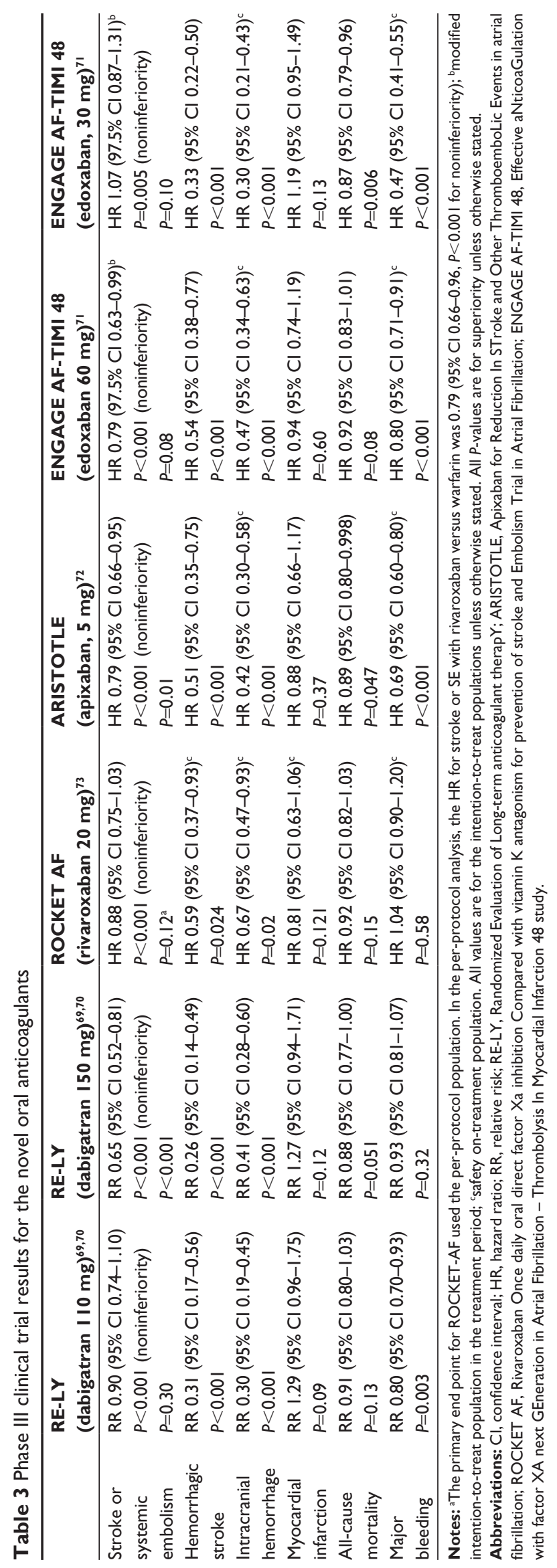




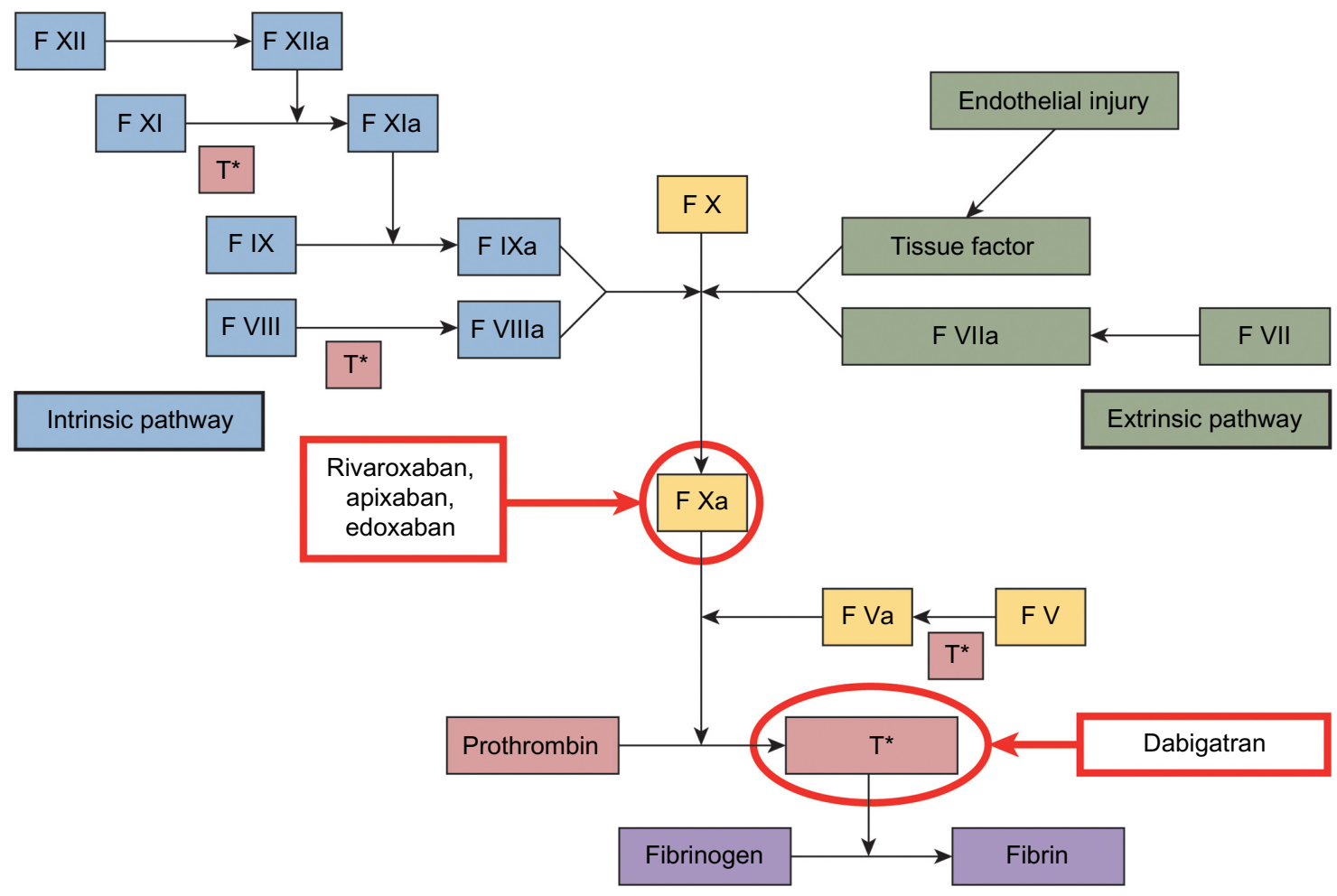

Figure I Sites of NOAC action in the coagulation cascade. Abbreviations: $\mathrm{F}$, factor; $\mathrm{T}^{*}$, thrombin.

interaction 0.16 and 0.34 for edoxaban $60 \mathrm{mg}$ and $30 \mathrm{mg}$ BID, respectively). ${ }^{71}$ No subgroup analyses by race have been published for the RE-LY (Randomized Evaluation of Longterm anticoagulant therapY) or ARISTOTLE (Apixaban for Reduction In STroke and Other ThromboemboLic Events in atrial fibrillation) trials, ${ }^{72,74}$ and no real-world data are currently available comparing the treatment effects of NOACs by race.

The prescribing information for dabigatran and rivaroxaban does not state whether any dose adjustments are needed for race, ${ }^{58,60}$ however, based on the results of a PK study in healthy subjects that showed no difference in apixaban PK among Caucasians, Asians, and African-Americans, the apixaban prescribing information states that no dose adjustment is required based on race/ethnicity. ${ }^{59}$

\section{Role of physicians and patients in stroke prevention in patients with AF}

There are disparities in stroke awareness between minority groups compared with Caucasians, including lack of awareness of stroke symptoms and signs and lack of knowledge about the need for urgent treatment and the causal role of risk factors. ${ }^{75}$ The Centers for Disease Control and Prevention analyzed data from an optional module of the 2005 Behavioral
Risk Factor Surveillance System that had used data from 13 US states and the District of Columbia to assess public awareness of stroke warning symptoms and the importance of seeking emergency care. The results showed that the proportion of respondents who were able to identify all five stroke warning signs and recognized the need to call emergency services was lower in African-Americans than in Caucasians (29.5\% versus $41.3 \%) .{ }^{76}$ This and other similar studies emphasize the need for educational efforts to improve knowledge about stroke symptoms among African-Americans. ${ }^{76-81}$

There are differences in attitudes, beliefs, and compliance among minority groups, including denial of disease, concern for potential or experienced side effects of medications, absence of symptoms, hierarchy of need, burden of filling prescriptions, attending doctor visits, and lower health literacy, all of which influence compliance with treatment. ${ }^{78}$ It is also important for physicians to evaluate the effects of health literacy, access to health care, and cultural barriers to anticoagulant use. ${ }^{82}$

Studies have shown that literacy decreases with age, and that this is more pronounced in African-American than Caucasian patients. ${ }^{82}$ Older patients receiving oral anticoagulants must become active participants in their own care, in that they and their families must read and comprehend written information 
regarding their treatment. ${ }^{82}$ It is also important to ensure that the reading materials supplied to patients with NVAF are sufficiently comprehensible to older adults. ${ }^{82}$ This may in part be easier with NOAC than with warfarin use, due to fewer food and drug interactions associated with NOACs.

\section{Conclusion}

AF is less common in African-Americans than in Caucasians; however, African-Americans have a higher risk of stroke. This could be due to African-Americans having a higher prevalence of other stroke-risk factors compared with Caucasians, although this may be an oversimplified view, as there are a number of other reasons why this disparity may occur. These include a need for more sensitive methods of detecting AF and a need for better access to health care and patient education for African-Americans. Warfarin-dose requirements vary across racial/ethnic groups, with African-American patients requiring a higher dose than Caucasians to maintain a therapeutic INR: the NOACs seem to differ in this regard, although data are currently limited. Minority racial groups are not proportionally represented in either real-world studies or clinical trials, and as more information becomes available and other social issues are addressed, the treatment disparities between African-American and Caucasian patients should decrease.

\section{Acknowledgments}

Professional medical writing and editorial assistance was provided by Claire Hall, $\mathrm{PhD}$, and Nicole Draghi, $\mathrm{PhD}$, at Caudex Medical, and was funded by Bristol-Myers Squibb and Pfizer Inc.

\section{Disclosure}

The author reports grant support from Bristol-Myers Squibb and Pfizer. The author reports no other conflicts of interest in this work.

\section{References}

1. American Heart Association. What is atrial fibrillation? 2013. Available from: http://www.heart.org/idc/groups/heart-public/@wcm/@hcm/ documents/downloadable/ucm_300294.pdf. Accessed October 30, 2013.

2. Furie KL, Goldstein LB, Albers GW, et al. Oral antithrombotic agents for the prevention of stroke in nonvalvular atrial fibrillation: a science advisory for healthcare professionals from the American Heart Association/ American Stroke Association. Stroke. 2012;43(12):3442-3453.

3. You JJ, Singer DE, Howard PA, et al. Antithrombotic therapy for atrial fibrillation: Antithrombotic Therapy and Prevention of Thrombosis, 9th ed: American College of Chest Physicians Evidence-Based Clinical Practice Guidelines. Chest. 2012;141(2 Suppl):e531S-e575S.

4. Alonso A, Agarwal SK, Soliman EZ, et al. Incidence of atrial fibrillation in whites and African-Americans: the Atherosclerosis Risk in Communities (ARIC) study. Am Heart J. 2009;158(1): 111-117.
5. Fuster V, Rydén LE, Cannom DS, et al. 2011 ACCF/AHA/HRS focused updates incorporated into the ACC/AHA/ESC 2006 guidelines for the management of patients with atrial fibrillation: a report of the American College of Cardiology Foundation/American Heart Association Task Force on practice guidelines. Circulation. 2011;123(10):e269-e367.

6. Camm AJ, Lip GY, De Caterina R, et al. 2012 Focused update of the ESC Guidelines for the management of atrial fibrillation: an update of the 2010 ESC Guidelines for the management of atrial fibrillation. Developed with the special contribution of the European Heart Rhythm Association. Eur Heart J. 2012;33(21):2719-2747.

7. Go AS, Mozaffarian D, Roger VL, et al. Heart disease and stroke statistics - 2013 update: a report from the American Heart Association. Circulation. 2013;127(1):e6-e245.

8. Furie KL, Kasner SE, Adams RJ, et al. Guidelines for the prevention of stroke in patients with stroke or transient ischemic attack: a guideline for healthcare professionals from the American Heart Association/ American Stroke Association. Stroke. 2011;42(1):227-276.

9. Marini C, De SF, Sacco S, et al. Contribution of atrial fibrillation to incidence and outcome of ischemic stroke: results from a populationbased study. Stroke. 2005;36(6):1115-1119.

10. Sudlow CL, Warlow CP. Comparable studies of the incidence of stroke and its pathological types: results from an international collaboration. International Stroke Incidence Collaboration. Stroke. 1997;28(3): 491-499.

11. Gage BF, Waterman AD, Shannon W, Boechler M, Rich MW, Radford MJ. Validation of clinical classification schemes for predicting stroke: results from the National Registry of Atrial Fibrillation. JAMA. 2001;285(22):2864-2870.

12. Lip GY, Nieuwlaat R, Pisters R, Lane DA, Crijns HJ. Refining clinical risk stratification for predicting stroke and thromboembolism in atrial fibrillation using a novel risk factor-based approach: the Euro Heart Survey on Atrial Fibrillation. Chest. 2010;137(2):263-272.

13. Benjamin EJ, Wolf PA, D’Agostino RB, Silbershatz H, Kannel WB, Levy D. Impact of atrial fibrillation on the risk of death: the Framingham Heart Study. Circulation. 1998;98(10):946-952.

14. Lin HJ, Wolf PA, Kelly-Hayes M, et al. Stroke severity in atrial fibrillation. The Framingham Study. Stroke. 1996;27(10):1760-1764.

15. Fuster V, Rydén LE, Cannom DS, et al. ACC/AHA/ESC 2006 guidelines for the management of patients with atrial fibrillation: a report of the American College of Cardiology/American Heart Association Task Force on practice guidelines and the European Society of Cardiology Committee for Practice Guidelines (Writing Committee to Revise the 2001 Guidelines for the Management of Patients With Atrial Fibrillation): developed in collaboration with the European Heart Rhythm Association and the Heart Rhythm Society. Circulation. 2006;114(7):e257-e354.

16. Deitelzweig S, Amin A, Jing Y, et al. Medical cost reductions associated with the usage of novel oral anticoagulants vs warfarin among atrial fibrillation patients, based on the RE-LY, ROCKET-AF and ARISTOTLE trials. J Med Econ. 2012;15(4):776-785.

17. Goldstein LB, Bushnell CD, Adams RJ, et al. Guidelines for the primary prevention of stroke: a guideline for healthcare professionals from the American Heart Association/American Stroke Association. Stroke. 2011;42(2):517-584.

18. Meschia JF, Merrill P, Soliman EZ, et al. Racial disparities in awareness and treatment of atrial fibrillation: the REasons for Geographic and Racial Differences in Stroke (REGARDS) study. Stroke. 2010;41(4): 581-587.

19. Smith SC Jr, Clark LT, Cooper RS, et al. Discovering the full spectrum of cardiovascular disease: Minority Health Summit 2003: report of the Obesity, Metabolic Syndrome, and Hypertension Writing Group. Circulation. 2005;111(10):e134-e139.

20. Soliman EZ, Prineas RJ, Case LD, Zhang ZM, Goff DC Jr. Ethnic distribution of ECG predictors of atrial fibrillation and its impact on understanding the ethnic distribution of ischemic stroke in the Atherosclerosis Risk in Communities (ARIC) study. Stroke. 2009;40(4):1204-1211. 
21. White H, Boden-Albala B, Wang C, et al. Ischemic stroke subtype incidence among whites, blacks, and Hispanics: the Northern Manhattan Study. Circulation. 2005;111(10):1327-1331.

22. Prineas RJ, Soliman EZ, Howard G, et al. The sensitivity of the method used to detect atrial fibrillation in population studies affects group-specific prevalence estimates: ethnic and regional distribution of atrial fibrillation in the REGARDS study. J Epidemiol. 2009;19(4): 177-181.

23. Jensen PN, Thacker EL, Dublin S, Psaty BM, Heckbert SR. Racial differences in the incidence of and risk factors for atrial fibrillation in older adults: the Cardiovascular Health Study. J Am Geriatr Soc. 2013;61(2):276-280.

24. Kolominsky-Rabas PL, Weber M, Gefeller O, Neundoerfer B, Heuschmann PU. Epidemiology of ischemic stroke subtypes according to TOAST criteria: incidence, recurrence, and long-term survival in ischemic stroke subtypes: a population-based study. Stroke. 2001;32(12): 2735-2740.

25. Lee BI, Nam HS, Heo JH, Kim DI. Yonsei Stroke Registry. Analysis of 1,000 patients with acute cerebral infarctions. Cerebrovasc Dis. 2001;12(3):145-151.

26. Petty GW, Brown RD Jr, Whisnant JP, Sicks JD, O'Fallon WM, Wiebers DO. Ischemic stroke subtypes: a population-based study of incidence and risk factors. Stroke. 1999;30(12):2513-2516.

27. Sacco RL, Ellenberg JH, Mohr JP, et al. Infarcts of undetermined cause: the NINCDS Stroke Data Bank. Ann Neurol. 1989;25(4):382-390.

28. Schneider AT, Kissela B, Woo D, et al. Ischemic stroke subtypes: a population-based study of incidence rates among blacks and whites. Stroke. 2004;35(7):1552-1556.

29. Schulz UG, Rothwell PM. Differences in vascular risk factors between etiological subtypes of ischemic stroke: importance of population-based studies. Stroke. 2003;34(8):2050-2059.

30. Christensen LM, Krieger DW, Højberg S, et al. Paroxysmal atrial fibrillation occurs often in cryptogenic ischaemic stroke. Final results from the SURPRISE study. Eur J Neurol. 2014;21(6):884-889.

31. Anderson JL, Halperin JL, Albert NM, et al. Management of patients with atrial fibrillation (compilation of $2006 \mathrm{ACCF} / \mathrm{AHA} / \mathrm{ESC}$ and 2011 ACCF/AHA/HRS recommendations): a report of the American College of Cardiology/American Heart Association Task Force on Practice Guidelines. J Am Coll Cardiol. 2013;61(18):1935-1944.

32. Ferguson C, Inglis SC, Newton PJ, Middleton S, Macdonald PS, Davidson PM. Atrial fibrillation: stroke prevention in focus. Aust Crit Care. 2014;27(2):92-98.

33. January CT, Wann LS, Alpert JS, et al. 2014 AHA/ACC/HRS Guideline for the Management of Patients With Atrial Fibrillation: Executive Summary: A Report of the American College of Cardiology/American Heart Association Task Force on Practice Guidelines and the Heart Rhythm Society. J Am Coll Cardiol. 2014;64(21):2246-2280.

34. Meschia JF, Bushnell C, Boden-Albala B, et al. Guidelines for the primary prevention of stroke: a statement for healthcare professionals from the American Heart Association/American Stroke Association. Stroke. 2014;45(12):3754-3832.

35. Camm AJ, Kirchhof P, Lip GY, et al. Guidelines for the management of atrial fibrillation: the Task Force for the Management of Atrial Fibrillation of the European Society of Cardiology (ESC). Eur Heart J. 2010;31(19):2369-2429.

36. Ibrahim SA, Kwoh CK, Harper DL, Baker DW. Racial differences in the utilization of oral anticoagulant therapy in heart failure: a study of elderly hospitalized patients. J Gen Intern Med. 2000;15(2):134-137.

37. Schwamm LH, Reeves MJ, Pan W, et al. Race/ethnicity, quality of care, and outcomes in ischemic stroke. Circulation. 2010;121(13):1492-1501.

38. Shen AY, Yao JF, Brar SS, Jorgensen MB, Wang X, Chen W. Racial/ethnic differences in ischemic stroke rates and the efficacy of warfarin among patients with atrial fibrillation. Stroke. 2008;39(10):2736-2743.

39. Apostolakis S, Sullivan RM, Olshansky B, Lip GY. Factors affecting quality of anticoagulation control among patients with atrial fibrillation on warfarin: the SAMe-TT(2)R(2) score. Chest. 2013;144(5): 1555-1563.
40. Henry J Kaiser Family Foundation. Examining sources of supplemental insurance and prescription coverage among Medicare beneficiaries; findings from the Medicare Current Beneficiary Survey. 2007. Available from: http://kff.org/medicare/report/examining-sources-of-supplementalinsurance-and-prescription. Accessed December 9, 2014.

41. Hanchate AD, Schwamm LH, Huang W, Hylek EM. Comparison of ischemic stroke outcomes and patient and hospital characteristics by race/ ethnicity and socioeconomic status. Stroke. 2013;44(2):469-476.

42. Bhattacharya P, Mada F, Salowich-Palm L, et al. Are racial disparities in stroke care still prevalent in certified stroke centers? J Stroke Cerebrovasc Dis. 2013;22(4):383-388.

43. Sacco RL, Kargman DE, Zamanillo MC. Race-ethnic differences in stroke risk factors among hospitalized patients with cerebral infarction: the Northern Manhattan Stroke Study. Neurology. 1995;45(4): 659-663.

44. Hart RG, Pearce LA, Aguilar MI. Meta-analysis: antithrombotic therapy to prevent stroke in patients who have nonvalvular atrial fibrillation. Ann Intern Med. 2007;146(12):857-867.

45. Bristol-Myers Squibb. Coumadin [prescribing information]. 2011. Available from: http://packageinserts.bms.com/pi/pi_coumadin.pdf. Accessed October 11, 2013.

46. Rosenman MB, Simon TA, Teal E, McGuire P, Nisi D, Jackson JD. Perceived or actual barriers to warfarin use in atrial fibrillation based on electronic medical records. Am J Ther. 2012;19(5):330-337.

47. Dang MT, Hambleton J, Kayser SR. The influence of ethnicity on warfarin dosage requirement. Ann Pharmacother. 2005;39(6): $1008-1012$.

48. Garwood CL, Clemente JL, Ibe GN, Kandula VA, Curtis KD, Whittaker P. Warfarin maintenance dose in older patients: higher average dose and wider dose frequency distribution in patients of African ancestry than those of European ancestry. Blood Cells Mol Dis. 2010;45(1):93-97.

49. Birman-Deych E, Radford MJ, Nilasena DS, Gage BF. Use and effectiveness of warfarin in Medicare beneficiaries with atrial fibrillation. Stroke. 2006;37(4):1070-1074.

50. Schauer DP, Johnston JA, Moomaw CJ, Wess M, Eckman MH. Racial disparities in the filling of warfarin prescriptions for nonvalvular atrial fibrillation. Am J Med Sci. 2007;333(2):67-73.

51. Thomas KL, Piccini JP, Liang L, et al. Racial differences in the prevalence and outcomes of atrial fibrillation among patients hospitalized with heart failure. J Am Heart Assoc. 2013;2(5):e000200.

52. Shen AY, Yao JF, Brar SS, Jorgensen MB, Chen W. Racial/ethnic differences in the risk of intracranial hemorrhage among patients with atrial fibrillation. J Am Coll Cardiol. 2007;50(4):309-315.

53. Cavallari LH, Aston JL, Momary KM, Shapiro NL, Patel SR, Nutescu EA. Predictors of unstable anticoagulation in African Americans. J Thromb Thrombolysis. 2009;27(4):430-437.

54. Perera MA, Cavallari LH, Limdi NA, et al. Genetic variants associated with warfarin dose in African-American individuals: a genome-wide association study. Lancet. 2013;382(9894):790-796.

55. Limdi NA, Beasley TM, Crowley MR, et al. VKORC1 polymorphisms, haplotypes and haplotype groups on warfarin dose among African-Americans and European-Americans. Pharmacogenomics. 2008;9(10):1445-1458.

56. Limdi NA, Arnett DK, Goldstein JA, et al. Influence of CYP2C9 and VKORC1 on warfarin dose, anticoagulation attainment and maintenance among European-Americans and African-Americans. Pharmacogenomics. 2008;9(5):511-526.

57. Daiichi Sankyo Co. Ltd. Savaysa ${ }^{\mathrm{TM}}$ (edoxaban) prescribing information. 2015. Available from http://www.accessdata.fda.gov/drugsatfda_docs/ label/2015/206316lbl.pdf. Accessed January 22, 2015.

58. Boehringer Ingelheim. Pradaxa dabigatran etexilate capsules [prescribing information]. Available from: http://www.accessdata. fda.gov/drugsatfda_docs/label/2013/022512s0171bl.pdf. Accessed September 18, 2013.

59. Bristol-Myers Squibb. Eliquis ${ }^{\circledR}$ (apixaban tablets) [prescribing information]. 2014. Available from: http://packageinserts.bms.com/ pi/pi_eliquis.pdf. Accessed March 20, 2014. 
60. Janssen Pharmaceuticals. Xarelto ${ }^{\circledR}$ (rivaroxaban tablets) [prescribing information]. 2014. Available from: http://www.xareltohcp.com/sites/ default/files/pdf/xarelto_0.pdf\#zoom=100. Accessed March 8, 2014.

61. Song Y, Wang X, Perlstein I, et al. Bioavailability of apixaban solution formulation and crushed tablet via nasogastric tube. Clin Pharmacol Ther. 2013;93 Suppl 1:S120-S121.

62. Boehringer Ingelheim. Study to evaluate the safety, pharmacokinetics and pharmacodynamics of BI 655075 administered alone or with dabigatran etexilate. Available from: http://clinicaltrials.gov/show/ NCT01688830. NLM identifier: NCT01688830. Accessed June 6, 2013.

63. Crowther M, Kitt M, Lorenz T, et al. A phase 2 randomized, double-blind, placebo-controlled trial of PRT064445, a novel, universal antidote for direct and indirect factor Xa inhibitors [Abstract]. J Thromb Haemost. 2013;11 Suppl 2:30.

64. Crowther M, Mathur V, Kitt M, et al. A phase 2 randomized, double-blind, placebo-controlled trial demonstrating reversal of rivaroxaban-induced anticoagulation in healthy subjects by andexanet alfa (PRT064445), an antidote for FXa inhibitors. Poster presented at: 55th ASH Annual Meeting and Exposition; December 7-10, 2013; New Orleans, LA.

65. Hollenbach SJ, Lu G, Tan S, et al. PRT064445 but not recombinant FVIIa reverses rivaroxaban induced anticoagulation as measured by reduction in blood loss in a rabbit liver laceration model. Poster presented at: 54th ASH Annual Meeting and Exposition; December 8-11, 2012; Atlanta, GA.

66. Laulicht B, Bakhru S, Lee C, et al. Small molecule antidote for anticoagulants. Circulation. 2012;126:A11395.

67. Perosphere. PER977: an anticoagulant reversal agent. 2013. Available from: http://perosphere.com/content/research/per977.htm. Accessed June 6, 2013.

68. van Ryn J, Litzenburger T, Waterman A, et al. Dabigatran anticoagulant activity is neutralized by an antibody selective to dabigatran in in vitro and in vivo models. J Am Coll Cardiol. 2011;57(14 Suppl 1):E1130.

69. Connolly SJ, Ezekowitz MD, Yusuf S, et al. Dabigatran versus warfarin in patients with atrial fibrillation. $N$ Engl J Med. 2009;361(12): 1139-1151.

70. Connolly SJ, Ezekowitz MD, Yusuf S, Reilly PA, Wallentin L. Newly identified events in the RE-LY trial. $N$ Engl J Med. 2010;363(19): $1875-1876$
71. Giugliano RP, Ruff CT, Braunwald E, et al. Edoxaban versus warfarin in patients with atrial fibrillation. $N$ Engl J Med. 2013;369(22): 2093-2104.

72. Granger CB, Alexander JH, McMurray JJ, et al. Apixaban versus warfarin in patients with atrial fibrillation. $N$ Engl J Med. 2011;365(11): 981-992.

73. Patel MR, Mahaffey KW, Garg J, et al. Rivaroxaban versus warfarin in nonvalvular atrial fibrillation. $N$ Engl J Med. 2011;365(10): 883-891.

74. Connolly SJ, Eikelboom J, Joyner C, et al. Apixaban in patients with atrial fibrillation. $N$ Engl J Med. 2011;364(9):806-817.

75. Cruz-Flores S, Rabinstein A, Biller J, et al. Racial-ethnic disparities in stroke care: the American experience: a statement for healthcare professionals from the American Heart Association/American Stroke Association. Stroke. 2011;42(7):2091-2116.

76. Centers for Disease Control and Prevention. Awareness of stroke warning symptoms - 13 states and the District of Columbia, 2005. MMWR Morb Mortal Wkly Rep. 2008;57(18):481-485.

77. Greenlund KJ, Neff LJ, Zheng ZJ, et al. Low public recognition of major stroke symptoms. Am J Prev Med. 2003;25(4):315-319.

78. Lutfiyya MN, Lipsky MS, Bales RW, Cha I, McGrath C. Disparities in knowledge of heart attack and stroke symptoms among adult men: an analysis of behavioral risk factor surveillance survey data. J Natl Med Assoc. 2008;100(10):1116-1124.

79. Lutfiyya MN, Cumba MT, McCullough JE, Barlow EL, Lipsky MS. Disparities in adult African American women's knowledge of heart attack and stroke symptomatology: an analysis of 2003-2005 Behavioral Risk Factor Surveillance Survey data. J Womens Health (Larchmt). 2008;17(5):805-813.

80. Lutfiyya MN, Ng L, Asner N, Lipsky MS. Disparities in stroke symptomology knowledge among US midlife women: an analysis of population survey data. J Stroke Cerebrovasc Dis. 2009;18(2):150-157.

81. Zerwic J, Hwang SY, Tucco L. Interpretation of symptoms and delay in seeking treatment by patients who have had a stroke: exploratory study. Heart Lung. 2007;36(1):25-34.

82. Wilson FL, Racine E, Tekieli V, Williams B. Literacy, readability and cultural barriers: critical factors to consider when educating older African Americans about anticoagulation therapy. J Clin Nurs. $2003 ; 12(2): 275-282$.
Journal of Multidisciplinary Healthcare

\section{Publish your work in this journal}

The Journal of Multidisciplinary Healthcare is an international, peerreviewed open-access journal that aims to represent and publish research in healthcare areas delivered by practitioners of different disciplines. This includes studies and reviews conducted by multidisciplinary teams as well as research which evaluates the results or conduct of such teams or
Dovepress

healthcare processes in general. The journal covers a wide range of areas and welcomes submissions from practitioners at all levels, from all over the world. The manuscript management system is completely online and includes a very quick and fair peer-review system. Visit http://www.dovepress.com/testimonials.php to read real quotes from published authors. 